\title{
Ectopic Meningioma in the Maxillary Alveolar Ridge: Report of a Case with a Review of the Literature
}

\author{
Hasan Onur Simsek, Nurgul Komerik
}

\begin{abstract}
Aim: Meningioma is a benign intracranial tumor. Occurrence of ectopic meningioma in maxillary alveolar ridge is very rare. Our aim is to add another case of ectopic meningioma in the maxillary alveolar ridge to the literature.
\end{abstract}

Background: Meningioma is a benign tumor that originates from meningocytes found in arachnoid villous structures of the meninges. The tumor is rarely seen in extracranial locations from the oral cavity.

Case description: We report on a 51-year-old edentulous woman with an ectopic meningioma on the right maxillary alveolar ridge. The patient had complained of dull pain and discharge from the right maxillary alveolar region. On clinical examination, we observed a lobulated lesion $2 \times 2 \mathrm{~cm}$ in size. Radiographic examination showed ill-defined radiolucency with irregular radiopaque areas. We also noted oroantral communication from the root of the lesion into to the maxillary sinus with bony destruction. We closed the oroantral communication by a buccal advancement flap. The histopathological diagnosis of the specimen was transitional type grade I meningioma. The patient's 5-year follow-up was uneventful.

Conclusion: The histological subtype of the meningioma dictates the mode of surgery. Hence, resection is not considered the treatment of choice for grade I lesions. It is important to keep in mind that meningioma is the differential diagnosis of the intraosseous mandible tumors.

Clinical significance: Ectopic meningioma is very rare. Meningioma should be considered as a differential diagnosis in clinical lesion. In the literature review, this is the fifth case report and review of the literature.

Keywords: Ectopic meningioma, Maxillary alveolar ridge, Tumor.

How to cite this article: Simsek HO, Komerik N. Ectopic Meningioma in the Maxillary Alveolar Ridge: Report of a Case with a Review of the Literature. Int J Experiment Dent Sci 2012;1(2):98-101.

\section{Source of support: Nil}

Conflict of interest: None declared

\section{BACKGROUND}

Meningioma is a benign tumor that originates from meningocytes found in arachnoid villous structures of the meninges. ${ }^{1}$ M eningiomas are the most common benign intracranial tumors, accounting for 13 to $26 \%$ of all primary intracranial tumors. The tumor is rarely seen in extracranial locations ( $2 \%$ of all meningiomas). ${ }^{2}$ Extracranial (heterotopic, ectopic, extracalvarial) tumors are mostly located in the head and neck region, the orbits being the predominant location. ${ }^{3}$ Tumors located in paranasal sinuses ${ }^{4}$ and nasal cavities ${ }^{5}$ have also been reported. However, meningioma originating from the oral cavity is extremely rare.

\section{CASE REPORT}

A 51-year-old edentulous woman presented to the clinic of oral and maxillofacial surgery complaining of dull pain and discharge from the upper right premolar/molar region for a duration of 6 months. She had the first molar extracted from this region by her dentist approximately 2 years previously. Examination revealed a $2 \times 2 \mathrm{~cm}$, lobulated, polyploidy tissue mass originating from the upper first molar area. Radiographic examination showed ill-defined radiolucency with irregular radiopaque areas (Fig. 1). We noted oroantral communication from the root of the lesion to the maxillary sinus. Together with the patient's history and clinical presentation, oroantral communication as a result of extraction of the first molar was our provisional diagnosis. With the patient under local anesthesia, we excised the lesion together with its extension into the sinus mucosa. We observed bone destruction extending toward the sinus floor, with necrotic bony fragments. We closed the oroantral communication by a buccal advancement flap.

W e sent the specimen for histopathological examination (Fig. 2). Microscopic examination of the tumor showed meningioma with whorled aspects and psammoma bodies. We observed positive reactivity with epithelial membrane antigen (EMA) and vimentin in neoplastic cells by immunohistochemical staining. The diagnosis was transitional type grade I meningioma.

A computed tomographic (CT) scan of the maxillary sinus revealed mucosa thickening of the right maxillary

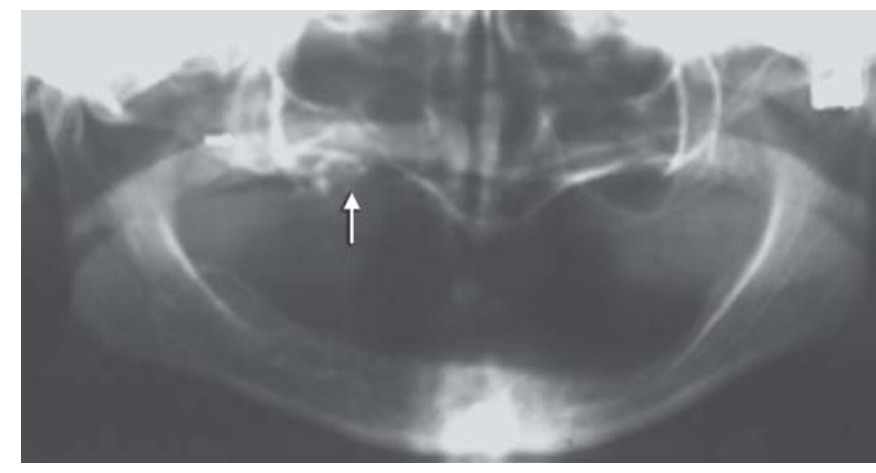

Fig. 1: Preoperative panoramic radiograph shows a mixed radiolucent-radiopaque lesion in the right posterior maxilla (arrow) 
sinus. To exclude maxillary sinus involvement, we performed a functional endoscopic surgery and biopsied sinus tissue. The histopathology diagnosis was fibrovascular soft tissue. Neurological evaluation of the patient revealed no neurologic symptoms or deficits. Further neurosurgical evaluation yielded no intracranial tumor. The patient's 5-year follow-up was uneventful (Figs 3 and 4).

\section{DISCUSSION}

Immunohistochemical staining is often useful to confirm the diagnosis of meningioma. ${ }^{6}$ The histopathologic

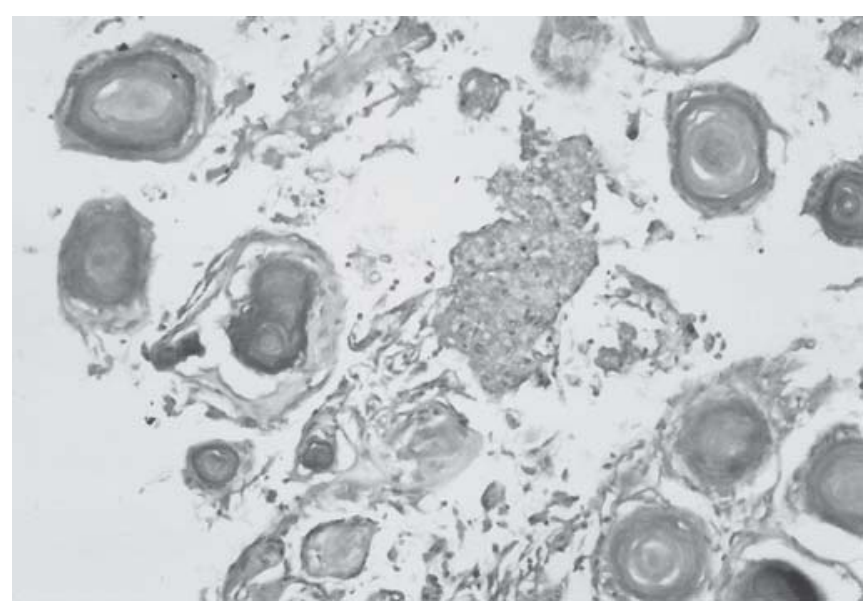

Fig. 2: Histopathological sections photomicrograph of tumor cells partly form a whorl formation, psammoma bodies (hematoxylineosin stain, original magnification $\times 100$ )

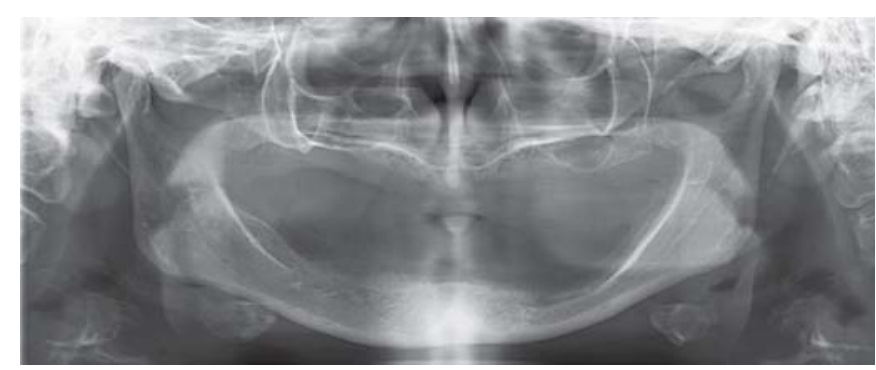

Fig. 3: Postoperative 5-year panoramic radiography

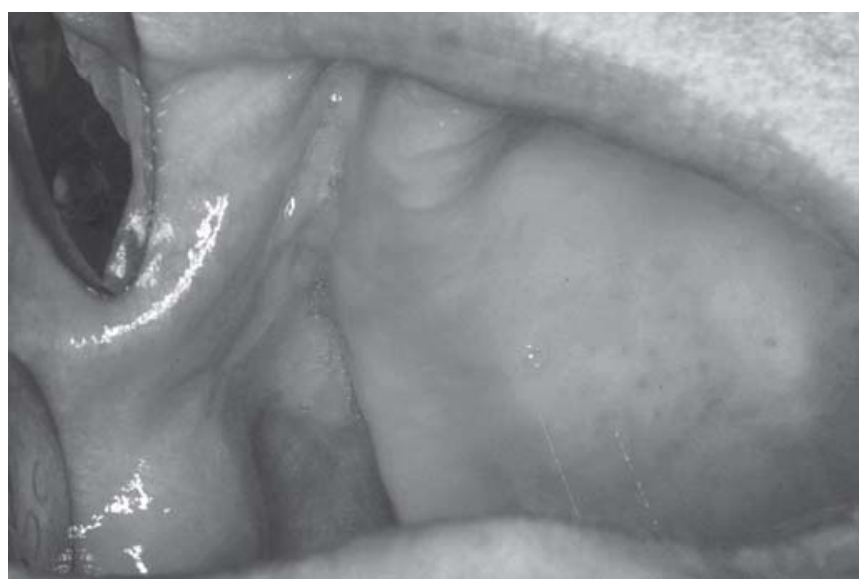

Fig. 4: Intraoral photograph showing normal maxillary alveolus mucosa and no oroantral communication on postoperative 5 years appearance of this tumor is very diverse. Currently, histological grading based on the W orld Health Organization (W HO) classification has been used. ${ }^{3}$ A ccordingly, grade I tumors have a low risk of recurrence or aggressive growth and include histological subtypes, namely meningothelial (syncytial), fibrous (fibroblastic), transitional (mixed), psammomatous, angiomatous, microcystic, secretory, lymphoplasmacyte-rich and metaplastic. Grade II tumors have a greater possibility of recurrence and/or aggressive behavior with histological subtypes of atypical, clear cell (intracranial) and chordoid. Grade III tumors have a high proliferative index and brain invasion. The subtypes are rhabdoid, papillary and anaplastic (malignant). In this case, the histological definite diagnosis was transitional meningioma, which falls into grade $I$.

The oral cavity is an extremely rare location for ectopic meningioma to be encountered; four cases in the maxilla ${ }^{7-10}$ and six in the mandible $\mathrm{e}^{11-15}$ have been reported in the English language literature. Table 1 shows details of all the cases reported previously in the literature. Although there is not a specific location pattern in the maxilla, in the mandible five out of six cases were located in the posterior region. In addition overall, all ectopic meningioma reported in the oral cavity except two were found in females. There is a wide age range (23-77 years) with a mean age of 55 years.

A lthough the tumor can originate directly from the oral cavity it may also be an extension of a tumor from neighboring structures. Brown et al (1976) reported a case with maxillary sinus, floor of the nasal cavity and maxillary gingival in the anterior region. The case was the first to present a periapical radiolucency diagnosed by a dental practitioner. ${ }^{7}$ A nother massive tumor including temporal fossa, zygoma, orbital, maxillary sinus and maxillary alveolar mucosa was diagnosed by a dental surgeon. ${ }^{10}$

Our case was situated in the maxillary alveolar ridge with maxillary sinus involvement. It is difficult to delineate the origin of the tumor. It may either stem from the maxillary mucosa growing toward the oral cavity or vice versa. The histological diagnosis of the tumor biopsy taken from the maxillary sinus mucosa was negative for the tumor. We presume that the tumor originated from the oral cavity as one would expect the tumors in the maxillary sinus to expand within the maxillary sinus mucosa more readily than in a direct invasion toward the oral cavity. Landini et al (1992) proposed that ectopic meningiomas in the alveolar ridges may develop as a result of stimulation of ectopic arachnoid tissue to proliferate via tooth extraction or chronic apical inflammation. ${ }^{11}$ 


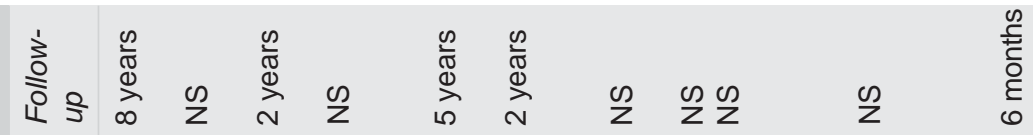

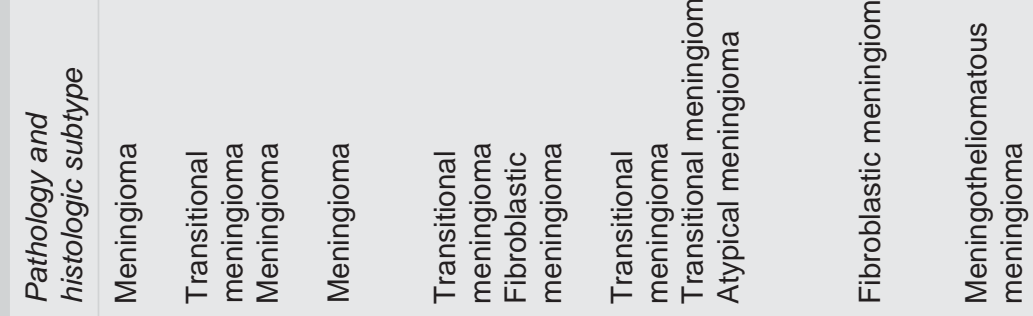

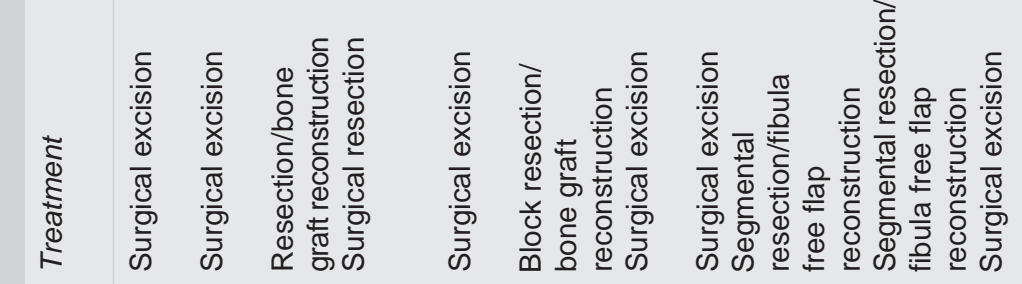

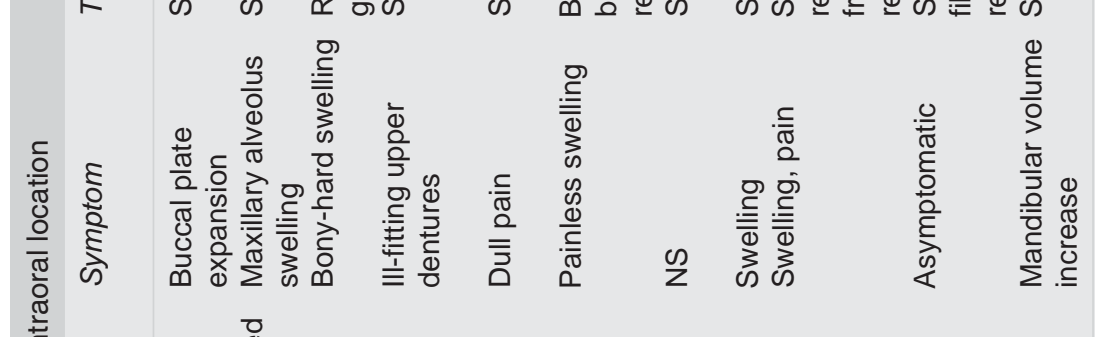

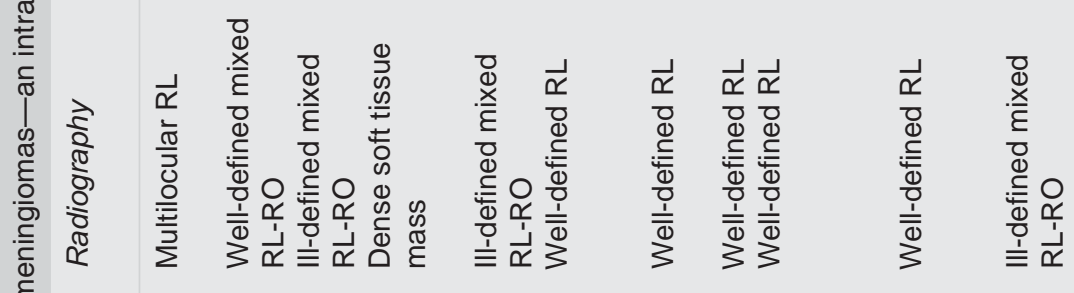

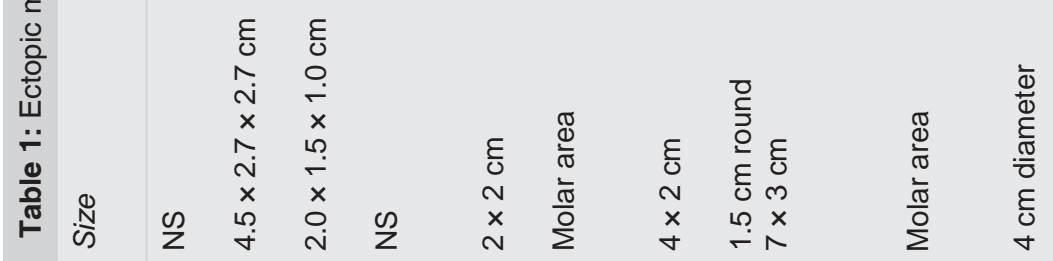

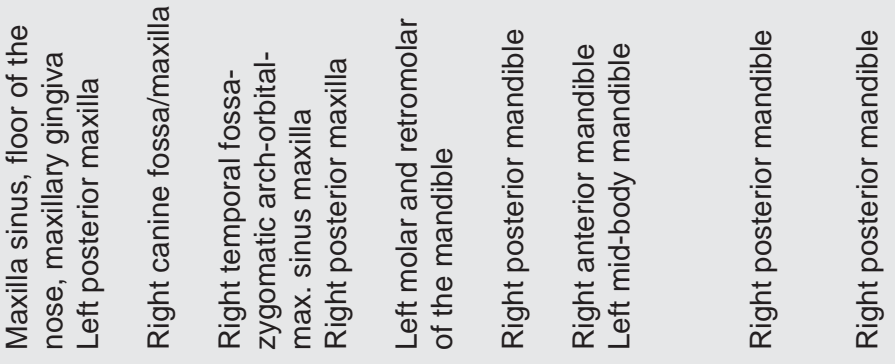
बำ

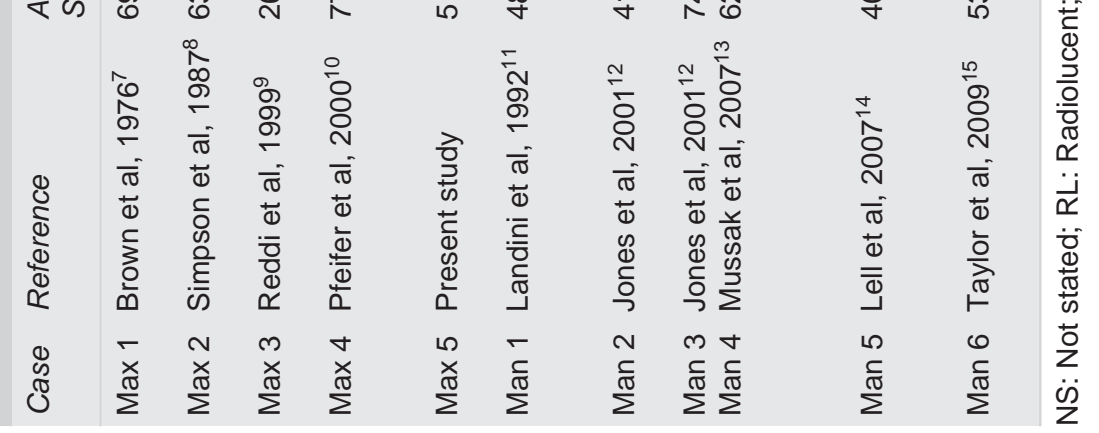


Ectopic Meningioma in the Maxillary Alveolar Ridge: Report of a Case with a Review of the Literature

\section{CONCLUSION}

The histological subtype of the meningioma dictates the mode of surgery. For instance, resection of the mandible may be carried out due to malignant nature of the lesion. ${ }^{13}$ Our case was a transitional type which has a low risk of recurrence or aggressive growth. Therefore, we do not plan to resection. We observed no recurrence during the 5 -year follow-up with the patient. Hence, resection is not considered the treatment of choice for grade I lesions. It is important to keep in mind that meningioma is the differential diagnosis of the intraosseous tumors of the jaws.

\section{CLINICAL SIGNIFICANCE}

Ectopic meningioma is very rare. Meningioma should be considered as a differential diagnosis in clinical lesion. In the literature review, this is the fifth case report and review of the literature.

\section{ACKNOWLEDGMENT}

The authors wish to acknowledge Professor Nilgun Kapucuoglu, (Department of Pathology, Faculty of Medicine, Suleyman Demirel University) for their contribution.

\section{REFERENCES}

1. Russell DS, Rubinstein LJ. Tumour of the meninges and related tissues. Pathology of tumours of the nervous system. In: Russel DS, Rubinstein LJ (Eds). London: Edward Arnold 1989:449532.

2. Friedman $C D$, Constantino PD, Teitel baum B, B erktold RE, Sisson GA Sr. Primary extracranial meningiomas of the head and neck. L aryngoscope 1990;100:41-48.

3. Laconnetta G, Santella A, Friscia M, A bbate V, Califano L. Extracranial primary and secondary meningiomas. Int J Oral M axillofac Surg 2012;41:211-17

4. Gokduman CA, Iplikcioglu A C, K uzdere M, B ek S, Cosar M . Primary meningioma of the paranasal sinus. J Clin Neurosci 2005;12:832-34.
5. Das S, Das D, A shraf K, Prinsley P. A n unusual nasal polyp: Skull base meningioma with extracranial extension into the nasal cavity. BrJ Hosp M ed 2012;73:46-47.

6. Kainuma K, Takumi $Y$, U ehara T, U sami SI. M eningioma of the paranasal sinus: A case report. A uris Nasus Larynx 2007;34:397-400.

7. Brown A M, Fordman K C, Lally ET. M eningiomas presenting as an intraoral mass. Oral Surg Oral Med Oral Pathol 1976;41:771-76.

8. Simpson MT, Sneddon KJ. Extracranial meningioma of oral cavity. Br J Oral M axillofac Surg 1987;25:520-25.

9. Reddi SP, Strauss SI, Strauss JE, Blanchaert HR Jr. A nterior maxillary lesion. J Oral M axillofac Surg 1999;57:1234-38.

10. Pfeifer JD, Hill A, Ramos CV, Wippold II FJ, Dehner LP. $M$ eningioma presenting as an intraoral mass in a patient with neurofibromatosis type 1. A rch Pathol L ab M ed 2000;124:898901.

11. Landini G, K itano M. Meningioma of the mandible. Cancer 1992;69:2917-20.

12. J ones A C, Freedman PD. Primary extracranial meningioma of the mandible: $A$ report of 2 cases and a review of the literature. Oral Surg Oral Med Oral Pathol Oral Radiol Endod 2001;91: 338-41.

13. Mussak EN, Holodny AI, Karimi SK. Meningioma of the mandible: Imaging with CT. Am J Neuroradiol 2007;28: 1157-59.

14. Lell M, Tudor $C$, A igner $T$, K essler P. Primary intraosseous meningioma of the mandible: $C T$ and $M R$ imaging features. A m J Neuroradiol 2007;28:129-31.

15. Taylor A M, Malagon HD, V aldez AM C, Hernandez AMM. Primary extracranial meningioma of the mandible. M ed Oral Pathol Oral Cir Bucal 2009;14:167-70.

\section{ABOUT THE AUTHORS}

\section{Hasan Onur Simsek (Corresponding Author)}

Research A ssistant, Department of Oral and Maxillofacial Surgery Faculty of Dentistry, Suleyman Demirel U niversity, Turkey e-mail: onursimsek@ sdu.edu.tr

\section{Nurgul Komerik}

Associate Professor, Department of Oral and M axillofacial Surgery Faculty of Dentistry, Suleyman Demirel University, Turkey 